\title{
Produtividade e perdas de amendoim em cinco diferentes datas de arranquio $^{1}$
}

\author{
Productivity and losses in the peanut on five different harvesting dates
}

\author{
Edvaldo Pereira dos Santos ${ }^{2 *}$, Rouverson Pereira da Silva ${ }^{3}$, Rafael Scabello Bertonha ${ }^{4}$, Rafael Henrique de \\ Freitas Noronha ${ }^{5}$ e Cristiano Zerbato ${ }^{4}$
}

\begin{abstract}
RESUMO - A colheita é momento crítico na produção do amendoim (Arachis hypogaea L.), porém, nesta operação as perdas são inevitáveis, podendo chegar, em alguns casos, a valores de até $30 \%$ da produtividade. O amendoim é cultivado em um curto período de tempo durante a reforma dos canaviais, o que proporciona melhor uso dos espaços agrícolas na região de Jaboticabal, SP. Objetivou-se com esta pesquisa definir a antecipação do arranquio do amendoim a partir da determinação da maturação. Realizou-se o arranquio do amendoim aos 120; 125; 130; 135 e 140 dias após a semeadura. Os resultados foram submetidos à análise de variância pelo teste $\mathrm{F}$ e quando houve significância das médias, aplicou-se o teste de Tukey a 5\% de probabilidade, mediante uso do diagrama de caixas para as variáveis: maturação, teor de água das vagens e do solo, resistência mecânica do solo à penetração, perdas na colheita e produtividade. O diagrama de caixas mostrou-se eficiente para a avaliação univariada das variáveis analisadas do amendoim, criando excelentes condições de visualização do comportamento das mesmas. Recomenda-se iniciar o arranquio do amendoim aos 120 DAS.
\end{abstract}

Palavras-chave: Amendoim. Plantas-maturação. Época de colheita.

\begin{abstract}
The harvest is a critical time in the production of the peanut (Arachis hypogaea L.), however in this operation losses are inevitable, in some cases of up to $30 \%$ of production. Peanuts are grown for a short period during the reform of the sugarcane fields, providing better usage of the agricultural spaces in Jaboticabal, São Paulo. The objective of this research was to see how early the peanuts could be dug up once they are seen to have matured. The peanuts were dug up at 120,125, 130, 135 and 140 days after sowing. Results were subjected to variance analysis by the F-test, and when there was significance of the averages, the Tukey test at 5\% probability was applied, using a box plot for the following variables: maturation, moisture content of pods and soil, mechanical resistance of soil to penetration, harvest loss and productivity. The box plot proved efficient in the univariate evaluation of the analyzed variables, creating excellent conditions for viewing their behavior. Digging up the peanuts at 120 DAS is recommended.
\end{abstract}

Key words: Peanut. Plants-maturation. Period of harvesting.

\footnotetext{
*Autor para correspondência

Recebido para publicação em 13/06/2012; aprovado em 18/06/2013

Parte da Dissertação de Mestrado do autor principal apresentada na UNESP/FCAV

${ }^{2}$ Departamento de Engenharia Rural, UNESP/FCAV, Via de Acesso Prof. Paulo Donato Castellane, s/n, Jaboticabal-SP, Brasil, 14.884-900, edypesantos@gmail.com

${ }^{3}$ Departamento de Engenharia Rural, UNESP/FCAV, Jaboticabal-SP, Brasil, rouverson@ @cav.unesp.br

${ }^{4}$ Programa de Pós-Graduação em Agronomia (Ciência do Solo), Departamento de Engenharia Rural, UNESP/FCAV, Jaboticabal-SP, Brasil, rsbertonha@agronomo.eng.br; cristianozerbato@hotmail.com

${ }^{5}$ Departamento de Engenharia Rural, UNESP/FCAV, Jaboticabal-SP, Brasil, rafnor86@yahoo.com.br
} 


\section{INTRODUÇÃO}

O estado de São Paulo é responsável por $71 \%$ da área e $77 \%$ da produção nacional de amendoim (Arachis hypogaea L.), sendo a região de Jaboticabal - SP responsável por $25 \%$ da produção do Estado e $20 \%$ da produção brasileira, apresentando também produtividade média elevada, em torno de 3,7 $\mathrm{t} \mathrm{ha}^{-1}$ contra $2,8 \mathrm{t} \mathrm{ha}^{-1}$ no Brasil e 1,6 t ha-1 no mundo (MARTINS, 2010).

A determinação do momento de início da colheita do amendoim é fundamental para se atingir máxima produtividade. Por se tratar de planta com hábito de crescimento indeterminado, mesmo quando a colheita ocorre em momento ótimo, o amendoim apresenta vagens em diferentes estádios de maturação (CARLEY et al., 2008; DORNER, 2008). Quando ocorre a colheita prematura, o grande número de vagens imaturas pode acarretar prejuízos econômicos para os produtores e indústria. Por outro lado, se realizada tardiamente, acarreta maiores perdas pela deterioração do pedúnculo das vagens em função da idade (ROWLAND et al., 2006). As perdas durante a retirada do amendoim do solo ocorrem devido à interação entre vários fatores relacionados ao cultivo e ao maquinário (SANTOS et al., 2010). Essas são inevitáveis, sendo a operação de arranquio mecanizado a que apresenta maiores perdas, devido principalmente ao enfraquecimento do pedúnculo pelo avançado estádio de maturação ou ainda, quando o solo encontra-se muito seco e compactado (ROBERSON, 2009). No Brasil as perdas encontradas nesta etapa variam de 3,1 a 47,1\% (MAHL et al., 2009; SANTOS et al., 2010). As perdas visíveis (vagens encontradas sobre o solo) relatadas na bibliografia variam entre 0,7 e $14,8 \%$ e as perdas invisíveis (vagens encontradas sob o solo), de 1,9 a 34,1\% (SANTOS et al., 2010). Nos Estados Unidos, Lamb et al. (2004) estimaram média de perdas no arranquio de 8 a $40 \%$, enquanto que Rowland et al. (2006) relataram perdas de até $50 \%$. Diante deste elevado índice de perdas, a otimização do projeto dos arrancadores de amendoim pode resultar em maior eficiência operacional, mas ainda assim, é fundamental a determinação de perdas na colheita para a manutenção dessa eficiência (BUTTS et al., 2009; PADMANATHAN et al., 2006).

Diante do curto período de tempo para o cultivo de amendoim nas áreas de renovação dos canaviais, e partindo da hipótese de que é possível definir o início do arranquio de amendoim na região de Jaboticabal - SP, a partir da determinação da maturação, de forma a se obter menores índices de perdas e sem alterações significativas na produtividade da cultura, o presente trabalho teve como objetivo avaliar as perdas e a produtividade do amendoim em cinco datas de início de colheita.

\section{MATERIAL E MÉTODOS}

O experimento foi conduzido em três propriedades no município de Jaboticabal - SP (Tabela 1), com área total avaliada de 20,1 ha de lavoura de amendoim da variedade Runner IAC 886, semeada com espaçamento de 0,90 m entre linhas. A cultura foi semeada no mês de outubro de 2009, com arranquio em fevereiro e março de 2010, aos 120; $125 ; 130 ; 135$ e 140 dias após a semeadura (DAS). As coordenadas geográficas são de $21^{\circ} 10^{\prime}$ de latitude Sul e 445' de longitude Oeste de Greenwich, com altitude média de $593 \mathrm{~m}$. O solo do local apresentou textura argilosa, variando entre 44 e $53 \%$ de argila (Tabela 1). Durante o período de condução da cultura os dados climatológicos (UNIVERSIDADE ESTADUAL PAULISTA, 2010) apresentaram-se conforme mostrado na Figura 1.

No arranquio, foi utilizado um trator da marca Massey Ferguson, modelo $680 \mathrm{HD}$, com potência máxima no motor de $127 \mathrm{~kW}(173 \mathrm{cv})$, a $2.000 \mathrm{rpm}$, em conjunto com um arrancador-invertedor da marca Santal, modelo AIA-2, 2 x 1 (duas linhas arrancadas, formando uma leira). Entretanto, para atender à recomendação do fabricante do arrancador-invertedor de $340 \mathrm{rpm}$ na TDP, o trator trabalhou à rotação de $1.500 \mathrm{rpm}$. Esta rotação foi utilizada, pois, apesar de resultar em condições não apropriadas de uso do ponto de vista mecânico, representa as condições reais de utilização do equipamento no campo, uma vez que o mesmo não apresenta mecanismos de redução capazes de proporcionar a rotação indicada.

As avaliações foram realizadas em delineamento inteiramente casualizado (DIC), com 36 repetições, sendo avaliadas cinco épocas de arranquio do amendoim (120; 125; 130; 135 e 140 DAS, correspondendo às áreas denominadas de I; II; III; IV e V, respectivamente). Foi demarcada em cada área uma malha regular na distância de $25 \times 50 \mathrm{~m}$, totalizando 36 pontos amostrais. As perdas foram classificadas em visíveis, invisíveis e totais do arranquio, que correspondem à soma das perdas visíveis e invisíveis. Para coletar esse material a leira formada após a passagem do arrancador foi cuidadosamente retirada, colocando-se neste local uma armação metálica de aproximadamente $2 \mathrm{~m}^{2}(1,11 \times 1,80 \mathrm{~m})$ transversalmente à leira, coletando-se manualmente as perdas visíveis e as perdas invisíveis localizadas até à profundidade de $0,15 \mathrm{~m}$. Adefinição da largura da armação correspondeu à largura de trabalho do arrancador-invertedor. Após a coleta as vagens foram acondicionadas em sacos de papel e identificadas. Posteriormente foram enviadas ao laboratório onde foram submetidas à lavagem para a retirada da terra aderida ao exocarpo. Sua massa foi mensurada em balança digital com precisão de 0,01 g. Em seguida, foram colocadas para secar em estufa, a $105 \pm 3{ }^{\circ} \mathrm{C}$, por 24 horas. Após a secagem a massa das vagens foi novamente determinada, 
Figura 1 - Climograma para o período de implantação e condução da cultura: a) precipitação e temperatura média; b) insolação e número de dias com chuva. Fonte: Universidade Estadual Paulista (2010)
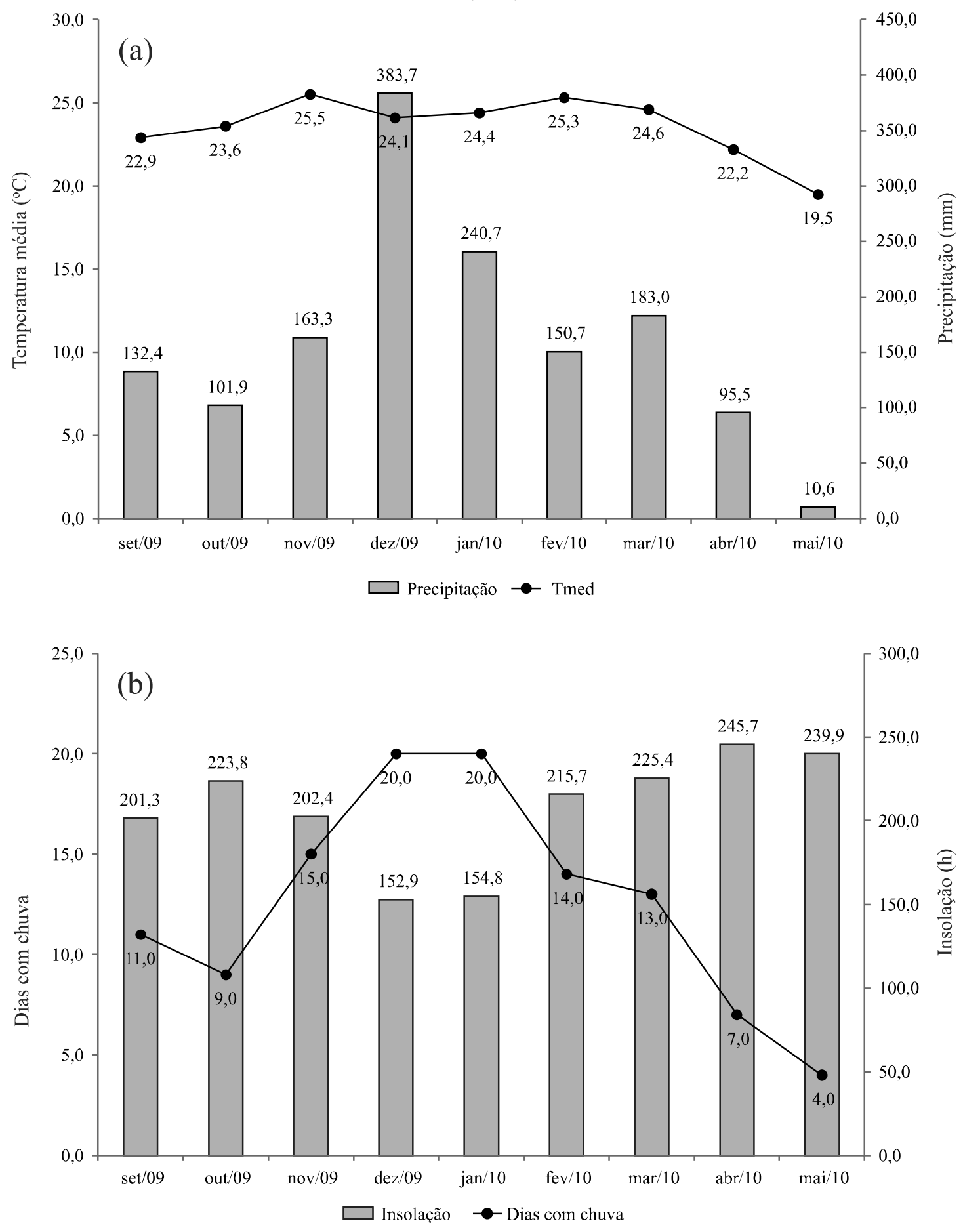

obtendo-se os valores das perdas que foram extrapolados para $\mathrm{kg} \mathrm{ha}^{-1}$, com posterior correção para $8 \%$ de teor de água. Os valores de perdas foram calculados em $\mathrm{kg} \mathrm{ha}^{-1} \mathrm{e}$ porcentagem em relação à produtividade.
Para amostragem da produtividade utilizou-se a mesma armação de aproximadamente $2 \mathrm{~m}^{2}$, anteriormente descrita, colocada sobre as leiras em todos os pontos amostrais. Procedeu-se o corte e ensacamento de todo 
Tabela 1 - Caracterização geral das áreas avaliadas

\begin{tabular}{|c|c|c|c|c|c|c|c|}
\hline \multirow{2}{*}{ Área } & & \multirow{2}{*}{ Ciclo (DAS) } & \multicolumn{2}{|c|}{ Operação/ Data } & \multirow{2}{*}{\multicolumn{2}{|c|}{ Composição (\%) }} & \multirow{2}{*}{$\begin{array}{c}\text { Solo } \\
\text { Textura }\end{array}$} \\
\hline & & & Semeadura & Arranquio & & & \\
\hline \multirow{3}{*}{ Estância Benvinda } & $\mathrm{I}$ & 120 & & $17 / 02 / 2010$ & Argila & 44 & \\
\hline & II & 125 & 20/10/2009 & $22 / 02 / 2010$ & Silte & 11 & Argilosa \\
\hline & II & 130 & & $27 / 02 / 2010$ & Areia & 45 & \\
\hline \multirow{3}{*}{ Sítio São José } & & & & & Argila & 53 & \\
\hline & IV & 135 & $26 / 10 / 2009$ & $10 / 03 / 2010$ & Silte & 19 & Argilosa \\
\hline & & & & & Areia & 28 & \\
\hline \multirow{3}{*}{ Sítio São Gabriel } & & & & & Argila & 48 & \\
\hline & $\mathrm{V}$ & 140 & $19 / 10 / 2009$ & 08/03/2010 & Silte & 6 & Argilosa \\
\hline & & & & & Areia & 46 & \\
\hline
\end{tabular}

material contido dentro da área da armação, e a partir das vagens encontradas dentro da área amostral, calculou-se a produtividade, a $8 \%$ de teor de água, valor este utilizado para o armazenamento do amendoim nas empresas beneficiadoras. Em seguida, determinou-se a produtividade bruta dalavoura, somando-se a produtividade de colheita com as perdas totais do arranquio. A avaliação de produtividade representa o material disponível para a operação posterior (recolhimento), ou seja, para os resultados de produtividade, não são consideradas as perdas do arranquio.

O teor de água das vagens (calculado em base úmida) foi obtido de acordo com método da estufa (BRASIL, 2009), coletando-se amostras após a passagem do arrancador-invertedor. As amostras para determinação do teor de água do solo foram coletadas utilizando-se um trado holandês na camada de 0,0 a $0,2 \mathrm{~m}$, sendo acondicionadas em recipientes de alumínio e levadas ao laboratório, onde permaneceram 24 horas em estufa a $105{ }^{\circ} \mathrm{C}$. O teor de água do solo foi obtido em base seca, conforme metodologia recomendada por Empresa Brasileira de Pesquisa Agropecuária (2006). A camada de 0,0 a 0,2 $\mathrm{m}$ foi definida para amostragem do teor de água do solo por ser a região onde se concentra a maior parte das vagens do amendoim, o que foi constatado em verificações realizadas a campo antes da colheita. Em cada ponto amostral foi retirada uma amostra de teor de água do solo, resultando em 36 amostras.

Para avaliação da maturação utilizou-se o método Hull scrape, que consiste na raspagem do exocarpo das vagens, expondo a coloração do mesocarpo. As vagens foram classificadas por cores de acordo com a Tabela de Classificação da Maturação do Amendoim, desenvolvida pela Universidade da
Georgia (WILLIAMS; DREXLER, 1981), nos Estados Unidos. Foram coletadas 100 vagens ao acaso em cada ponto avaliado, sendo determinada a maturação de acordo com o método Hull scrape, considerando-se as classes preta, marrom e laranja para determinar a porcentagem de maturação da área.

A avaliação da resistência mecânica do solo à penetração (RMSP) foi realizada em cada ponto (totalizando 36 amostras), antes do início da colheita, utilizando-se o penetrômetro eletrônico DLG modelo PNT-2000/MOTOR, coletando-se resultados até a profundidade de $0,20 \mathrm{~m}$, com intervalo de uma leitura por centímetro.

A análise estatística dos dados foi realizada utilizando-se o programa Minitab $16^{\circledR}$ para o cálculo das medidas de posição (média e mediana), de dispersão (distância interquartílica), de assimetria e valores discrepantes. Quando procedente, realizou-se a análise de variância fator único, a 5\% de probabilidade, para verificar a existência ou não de diferenças entre as médias das variáveis analisadas, empregando-se os diagramas de caixa (box plot). O diagrama de caixas é um gráfico que possibilita representar a distribuição de um conjunto de dados com base em alguns de seus parâmetros descritivos, como a mediana (Q2), o quartil inferior (Q1), o quartil superior (Q3), intervalo interquartil (IQR = Q3 - Q1), e os valores mínimos e máximos (Figura 2). Esta análise permite avaliar a simetria e dispersão dos dados, e a existência de pontos discrepantes (outliers), sendo especialmente adequada para a comparação de dois ou mais conjuntos de dados correspondentes às categorias de uma variável. 
Figura 2 - Principais características de um gráfico tipo diagrama de caixas

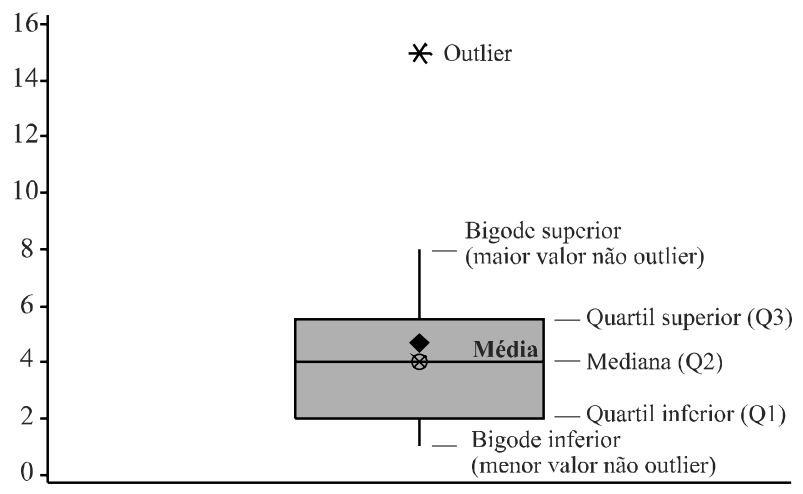

\section{RESULTADOS E DISCUSSÃO}

A porcentagem de maturação (Figura 3A) apresentou maior variabilidade aos 120 e 140 dias após a semeadura (DAS), o que fica evidenciado pelo maior intervalo interquartil encontrado nestas duas avaliações. A maturação aos 125 DAS diferiu da ordem de $4 \%$ das avaliações realizadas aos 130 e 135 DAS, ocorrendo também distribuição assimétrica mais acentuada dos resultados aos 125 DAS, com concentração de valores à esquerda da distribuição, ou seja, indicando a concentração de maior quantidade de pontos com menores porcentagens de maturação nesta área. As menores médias observadas aos 130 e 135 DAS (áreas III e IV) em relação aos 125 DAS (área II) podem ser explicadas pela presença de outliers com valores abaixo de $65 \%$ de maturação. A proximidade entre os valores das médias e medianas indica que houve pouca variabilidade da porcentagem de maturação nas áreas avaliadas, o que pode ter sido ocasionado pelo atraso do florescimento ocorrido na safra 2009/2010, em virtude do excesso de chuvas. Nos Estados Unidos, Branch et al. (2010) testaram seis datas de arranquio $(127 ; 134 ; 141 ; 148 ; 155$ e 162 DAS) encontrando maior percentual de vagens maduras aos 148 a 162 DAS, o que no entanto, não foi observado no presente trabalho (Figura 3A).

O teor de água das vagens (Figura 3B) e do solo (Figura 3C) seguiram a mesma tendência, sendo observados menores valores de teor de água das vagens para a área II (125 DAS). Também o teor de água das vagens (Figura 3B) apresentou maior intervalo interquartil para a avaliação realizada aos 140 DAS. Verificou-se que o teor de água das vagens de amendoim variou de 36 a $38 \%$ (Figura3B). Respostas semelhantes foram constatadas por Segato e Penariol (2007), que encontram teor de água das vagens de 35 a $45 \%$ no momento do arranquio.

Para o teor de água no solo, foram encontradas diferenças entre as áreas colhidas aos 125 e 135 DAS, com presença de pontos discrepantes nas análises
Figura 3 - Maturação das vagens (A), teor de água das vagens (B) e teor de água no solo (C) no arranquio de amendoim na safra 2009/2010
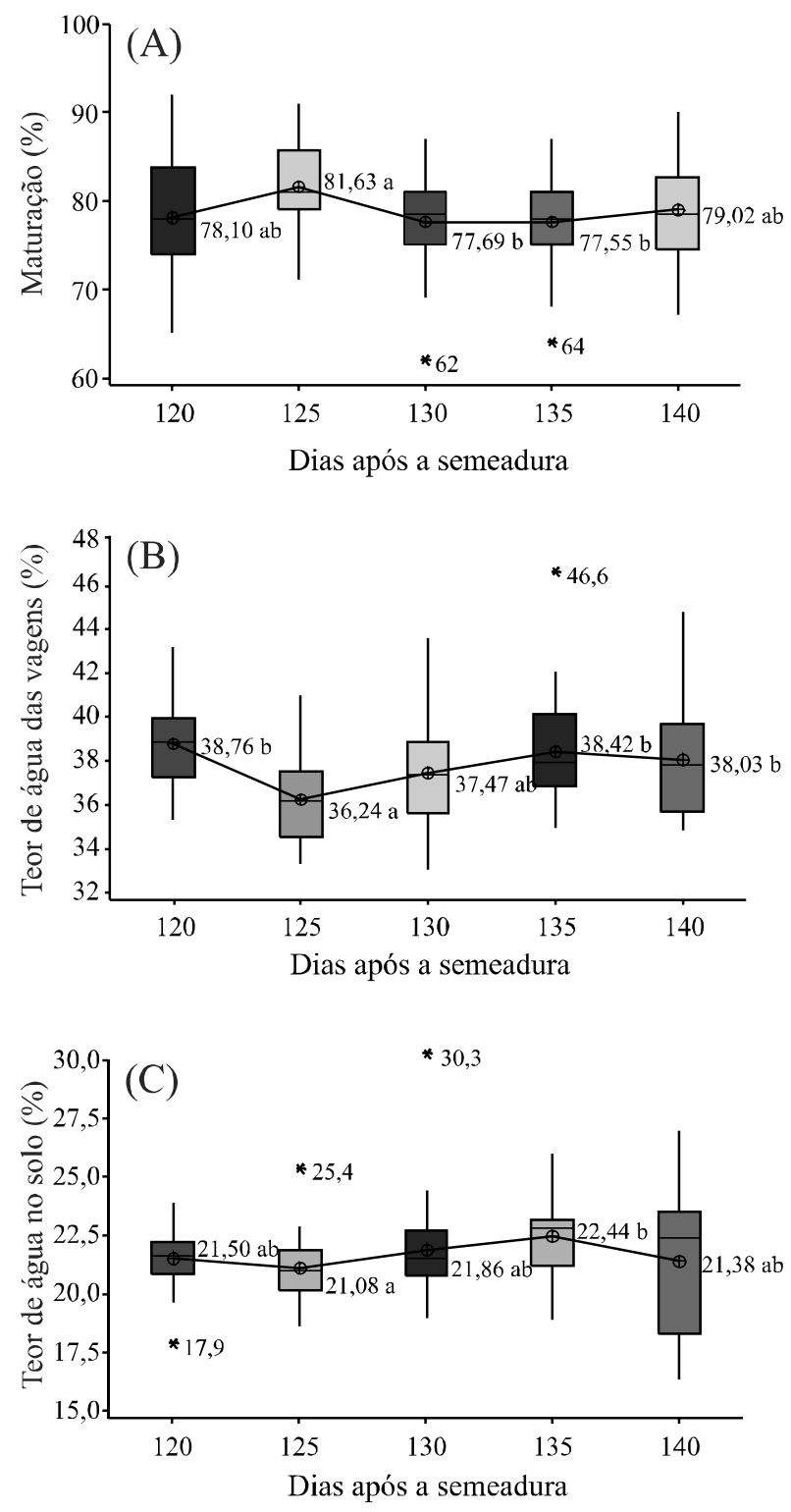

de 125 e 130 DAS. A distribuição dos resultados do teor de água do solo foi assimétrica (Figura 3C), com concentração à direita (maiores valores) nas avaliações de 135 e 140 DAS, apresentando grande variabilidade dos resultados nesta última avaliação.

Segundo Ince e Guzel (2003), a resistência do ginóforo ao rompimento (GBR) é um importante fator para designar as perdas no arranquio e recolhimento do amendoim, sendo dependente do período de floração. Para estes autores existe uma relação exponencial entre a resistência do ginóforo ao rompimento e o teor de água do 
solo, de forma que quando diminui o teor de água, diminui a GBR e, consequentemente, aumentam as perdas totais na colheita. Neste contexto é de se esperar que as perdas no arranquio sejam maiores na área IV (135 DAS) em relação à área II (125 DAS).

As médias dos valores de resistência mecânica do solo à penetração (RMSP) (Figura 4A) se encontram próximas às medianas, indicando haver distribuição normal dos resultados, com maior variabilidade nas avaliações de 120 e 135 DAS. Os menores valores da RMSP se encontram nas áreas cujo arranquio foram realizados aos 125; 130 e $140 \mathrm{DAS}$, quando comparadas às áreas com arranquio aos 120 e 135 DAS, comportamento este que pode ser considerado aleatório, uma vez que o teor de água de solo aos 120 DAS não diferiu dos valores encontrados nas outras datas de arranquio, enquanto que o teor de água do solo para o arranquio realizado aos 135 DAS somente diferiu do arranquio aos 125 DAS. Leonel et al. (2007); Beutler et al. (2008) afirmaram que valores acima de $2 \mathrm{MPa}$ são limitantes à cultura do amendoim, além de constatarem que a produtividade do amendoim decresceu linearmente com o aumento da compactação. Grotta et al. (2008) avaliaram que não houve diferença na produtividade para as diferentes compactações, porém estes autores trabalharam com compactações abaixo de $1 \mathrm{MPa}$. Considerando que a resistência do ginóforo ao rompimento (GBR) pode estar relacionada com as perdas na colheita do amendoim (INCE; GUZEL, 2003), e que a mesma depende, dentre outros fatores, da estrutura do solo, é esperado que as perdas totais sejam maiores nas áreas I e IV (120 e 135 DAS, respectivamente) em relação às demais áreas, uma vez que estas duas áreas apresentaram valores médios de RMSP acima de 2 Mpa (Figura 4A).

A distribuição das perdas invisíveis do arranquio (PIA) (Figura 4B) pode ser considerada assimétrica em relação à mediana, com concentração dos resultados à direita, para a avaliação dos 140 dias, e simétrica para as demais avaliações, com pouca variabilidade dos resultados. A maior porcentagem de perda, e maior variabilidade dos resultados ocorreram na avaliação de 140 DAS, com perdas $350 \%$ maiores que a média das perdas encontradas nas outras avaliações. Devido ao elevado número de pontos amostrais em cada área, a ocorrência de pontos discrepantes em todas as avaliações de PIA não chegou a interferir negativamente na qualidade amostral. Os valores de perdas visíveis do arranquio (PVA) (Figura 4C) situaram-se entre 1,6 a 4,6\%, encontrando-se abaixo dos valores citados por Mahl et al. (2009); Santos et al. (2010), que encontraram perdas visíveis de até $14,8 \%$. Observa-se que houve aumento gradativo de PVA com o aumento do tempo de permanência da cultura no campo, com maiores perdas observadas na avaliação de 140 DAS, acompanhando os resultados de perdas invisíveis (Figura 4B), com maior variabilidade dos
Figura 4 - Resistência mecânica do solo à penetração (A), perdas invisíveis (B) e perdas visíveis (C) no arranquio de amendoim na safra 2009/2010
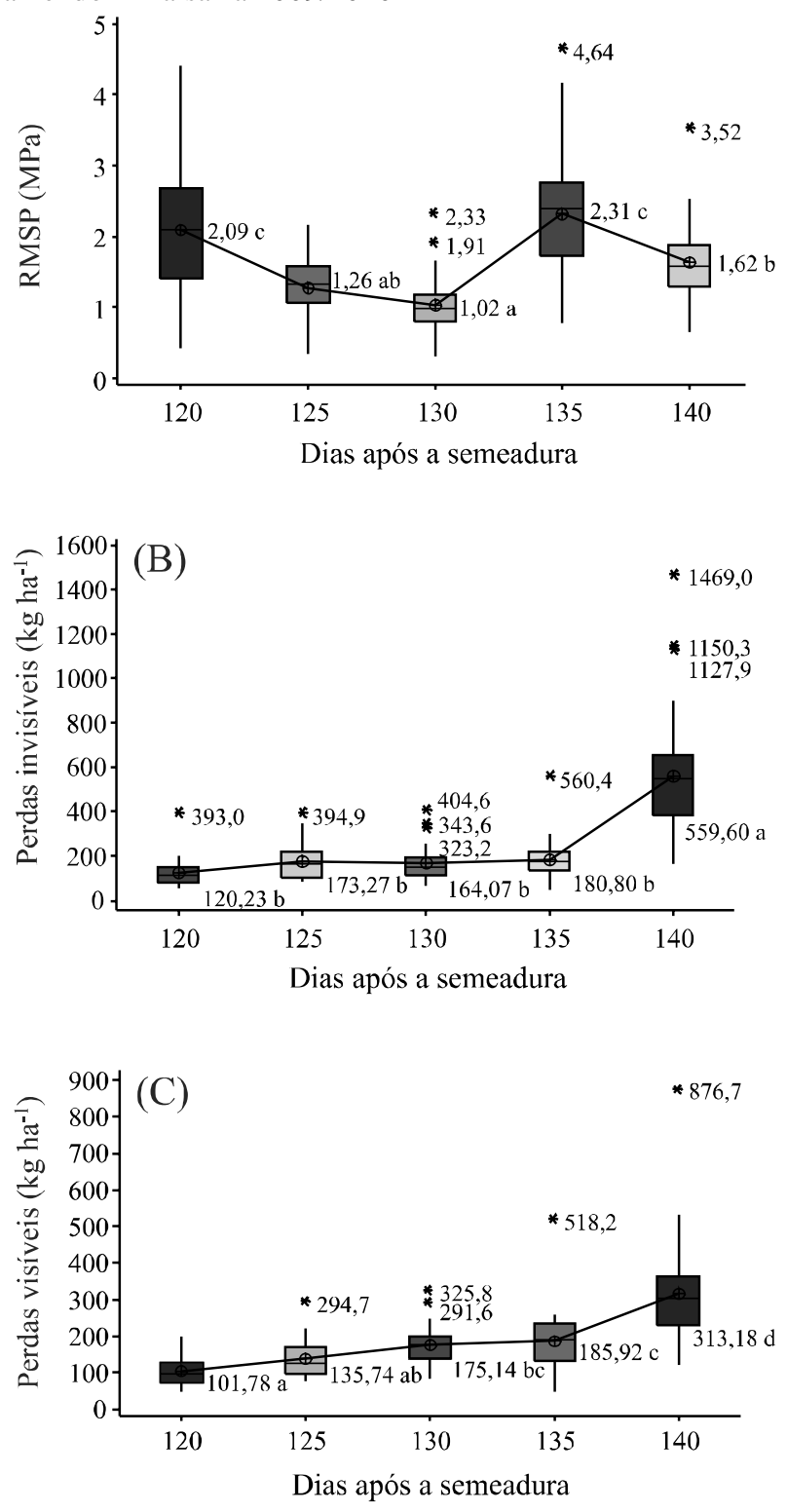

resultados aos 140 DAS. Assim, pode-se inferir que, no tangente às perdas no arranquio, quanto mais tempo a cultura permanece no campo, mais o processo de colheita tende a ficar instável.

Para as perdas totais do arranquio (PTA) (Figura 5A) corroboram com os valores encontrados por Santos et al. (2010). Observou-se a mesma tendência do experimento realizado na safra anterior (2008/2009), em que as perdas encontradas nas áreas colhidas com até 135 dias foram menores, e mais homogêneas, em relação à área colhida com 140 DAS. Lamb et al. (2004) relataram que as 
perdas no arranquio são estimadas em $8 \%$ da produção total, mas que podem chegar a $40 \%$ quando o arranquio é realizado além do ponto ótimo de colheita. Como no presente trabalho a maturação foi adequada à realização da colheita em todas as áreas avaliadas, ou seja, acima de $70 \%$, as perdas totais encontradas foram de, no máximo, 12,7\% (Figura 5A), corroborando com o que foi postulado por Lamb et al. (2004).

A variabilidade dos resultados de produtividade (Figura 5B) foi semelhante em todas as avaliações, apresentando médias próximas às medianas, com exceção da avaliação de 125 DAS, que apresenta distribuição

Figura 5 - Perdas totais (A), produtividade (B) e produtividade bruta (C) no arranquio de amendoim na safra 2009/2010
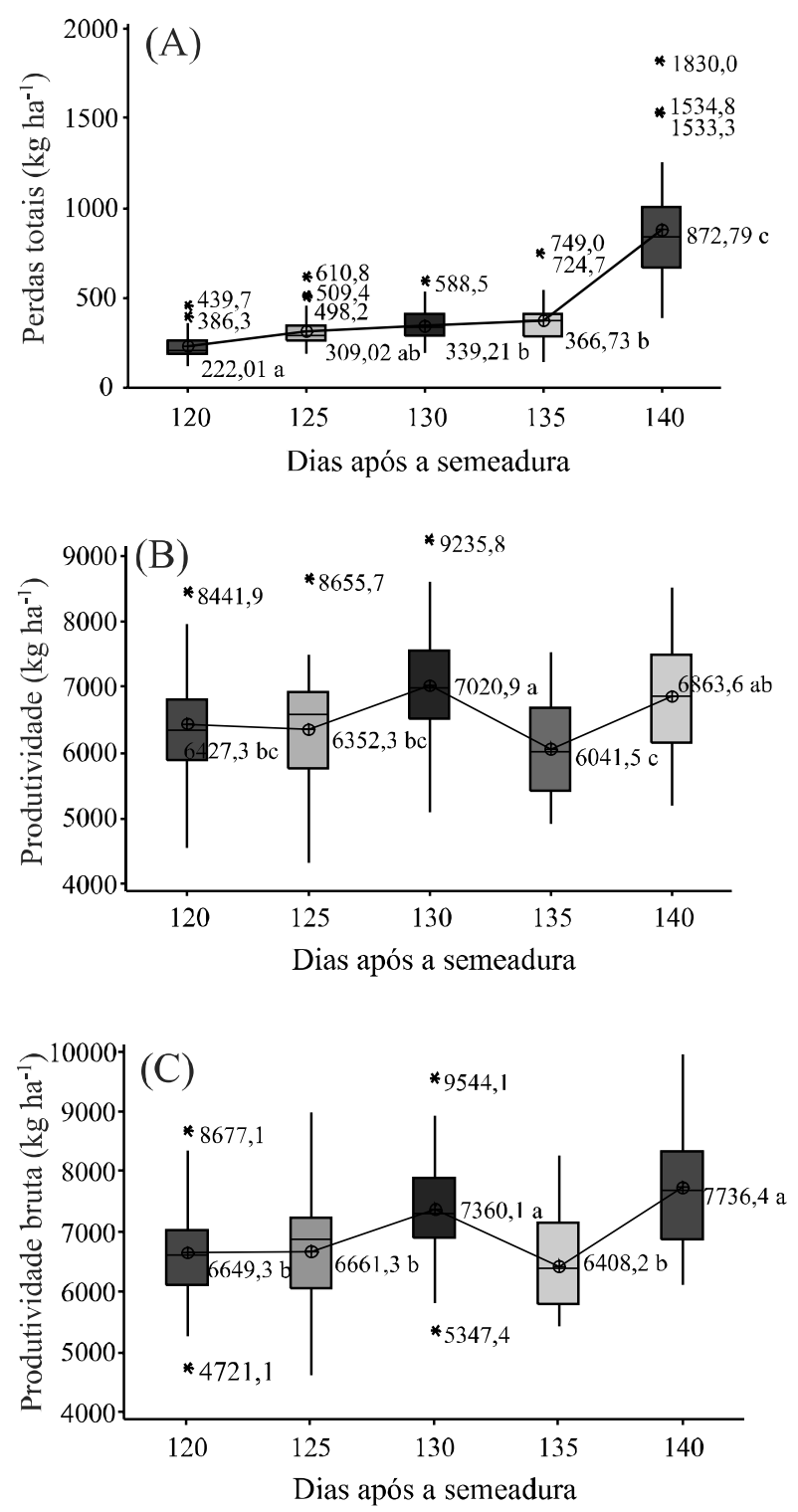

assimétrica, com concentração à direita. A produtividade na área colhida aos 130 DAS foi superior às das áreas com arranquio aos 120; 125 e 135 DAS, diferindo dos encontrados por Branch et al. (2010), que avaliando seis datas de arranquio $(127 ; 134 ; 141 ; 148 ; 155$ e 162 DAS) nos EUA durante as safras de 2005 a 2009, obtiveram maior produtividade para avaliações aos 141 e 155 DAS em comparação com as demais datas, confirmando que a produtividade não é diretamente proporcional ao tempo que a cultura permanece no campo, e que existem a atuação de outras variáveis nesse processo. Da mesma maneira, no presente trabalho, o fato de a produtividade ter sido estatisticamente igual nas avaliações realizadas aos 120 e 140 DAS reafirma que o maior tempo de permanência da cultura no campo não é por si só um fator de garantia do aumento da produtividade.

Analisando a produtividade bruta (Figura 5C) pode-se observar que nas áreas colhidas aos 130 e 140 DAS foram superiores às das demais áreas. Considerando-se estas áreas, observa-se que perdas totais do arranquio representaram 4,6 e 11,2\% da produtividade bruta aos 130 e 140 DAS, respectivamente. Para a área de 120 DAS, as perdas situaram-se em torno de 3,3\% da produtividade bruta. Desta forma, verifica-se que a maior permanência da cultura do campo acarretou o aumento das perdas do arranquio em 7,9\%. Descontando-se as perdas, constata-se que não houve diferença para as produtividades aos 120 e 140 DAS, confirmando a hipótese inicialmente estabelecida de que é possível adiantar a colheita de amendoim sem acarretar diminuição da produtividade.

Apesar das suposições em relação ao aumento das perdas em função da diminuição do teor de água dos solos ou do aumento da RMSP, este fato não foi observado no presente trabalho, o que pode ser justificado pela ocorrência de pontos discrepantes nas perdas totais.

\section{CONCLUSÕES}

1. O arranquio de amendoim pode ser antecipado em 20 dias (de 140 para 120 DAS) sem acarretar diminuição da produtividade e/ou aumento das perdas com essa antecipação;

2. A maturação fisiológica ocorre a partir dos 120 dias após a semeadura;

3. O ganho de produtividade obtido com o adiamento do arranquio foi relativizado pelo aumento das perdas totais;

4. A diminuição do teor de água dos solos e o aumento da RMSP não afetaram o aumento das perdas. 


\section{REFERÊNCIAS}

BEUTLER, A. N. et al. Densidade do solo relativa e parâmetro "S" como indicadores da qualidade física para culturas anuais. Revista de Biologia e Ciências da Terra, v. 8, n. 2, p. 27-36, 2008.

BRANCH, W. D. et al. Determination of the relative maturity range for the 'Georgia-02C' peanut cultivar. Peanut Science, v. 37, n. 2 , p. 106-109, 2010.

BRASIL. Ministério da Agricultura e Reforma Agrária. Regras para análise de sementes. Brasília: Mapa/ACS, 2009. 399 p

BUTTS, C. L. et al. Performance of equipment for in-field shelling of peanut for biodiesel production. Transactions of the ASABE, v. 52, n. 5, p. 1461-1469, 2009.

CARLEY, D. S. et al. Peanut Response to Planting Date and Potential of Canopy Reflectance as an Indicator of Pod Maturation. Agronomy Journal, v. 100, n. 2, p. 376-380, 2008.

DORNER, J. W. Relationship between kernel moisture content and water activity in different maturity stages of peanut. Peanut Science, v. 35, n. 2, p. 77-80, 2008.

EMPRESA BRASILEIRA DE PESQUISA AGROPECUÁRIA. Centro Nacional de Pesquisa de Solos. Sistema brasileiro de classificação de solos. 2. ed. Rio de Janeiro, 2006. 306 p.

GROTTA, D. C. C. et al. Influência da profundidade de semeadura e da compactação do solo sobre a semente na produtividade do amendoim. Ciência e Agrotecnologia, v. 32, n. 2, p. 547-552, 2008.

INCE, A.; GUZEL E. Effects of gynophore breaking resistance on losses in mechanized peanut harvesting. In: INTERNATIONAL CONFERENCE ON CROP HARVESTING AND PROCESSING, 2003, Louisville, Kentucky. Proceedings... St Joseph: ASABE. 2003. p. 1103.

LAMB, M. C. et al. Impact of sprinkler irrigation amount and rotation on peanut yield. Peanut Science, v. 31, n. 2, p. 108-113, 2004.
LEONEL, C. L. et al. Relação da compactação do solo com a cultura do amendoim. Bioscience Journal, v. 23, n. 2, p. 70-81, 2007.

MAHL, D. et al. Perdas no arranquio mecanizado do amendoim em função da velocidade de deslocamento e espaçamento entre hastes. In: Congresso Brasileiro de Engenharia Agrícola, 38., 2009, Petrolina. Anais..., Jaboticabal: SBEA, 2009. 1 CD-ROM.

MARTINS, R. Amendoim: safra 2008/09 e perspectiva para 2009/10. Análises e indicadores do agronegócio. v. 5, n. 1, p. 1-4, 2010.

PADMANATHAN, P. K. et al. Design, development and evaluation of tractor operated groundnut combine harvester. Journal of Applied Sciences Research, v. 12, n. 2, p. 1338-1341, 2006.

ROBERSON, G. T. Planting, harvesting, and curing peanuts. p.131-148. In: JORDAN, D. L. et al. ; Peanut information 2010. North Carolina Coop. Ext. Ser. Series AG-331. 2009.

ROWLAND, D. L. et al. Determination of maturity and degree day indices and theirs success in predicting peanut maturity. Peanut Science, v. 33, n. 2, p. 125-136, 2006.

SANTOS, E. P. et al. Perdas na colheita mecanizada de amendoim. In: CONGRESO LATINOAMAERICANO Y DEL CARIBE DE INGENIERÍA AGRÍCOLA, 9., 2010, Vitória. Anais..., Vitória: SBEA, 2010. 1 CD-ROM

SEGATO, S. V.; PENARIOL, A. L. A cultura do amendoim em áreas de reforma de canavial. In: SEGATO, S. V.; FERNANDES, C.; SENE PINTO, A. Expansão e Renovação de Canavial. Piracicaba: Editora CP 2, 2007, p. 85-116.

UNIVERSIDADE ESTADUAL PAULISTA "JÚLIO DE MESQUITA FILHO'.Estação meteorológica. Dados meteorológicos mensais dos anos de 2009 e 2010 em Jaboticabal. Disponível em: $<$ http://www.exatas.fcav.unesp.br/ estacao/est_tab_meteor_01_02.htm>. Acesso em: 15 ago. 2010.

WILLIAMS, E. J., DREXLER, J. S. A non-destructive method for determining peanut pod maturity. Peanut Science, v. 8, n. 2, p. 134-141, 1981 